\title{
Toxicity Assessment of Products of Combustion of Flexible Polyurethane Foam
}

\author{
CRAIG BEYLER \\ Hughes Associates, Inc. \\ 3610 Commerce Drive, Suite 817 \\ Baltimore, MD 21227 USA
}

\begin{abstract}
The scientific literature on the toxicity of products of combustion of flexible polyurethane foam is reviewed to assess its potential for use in toxic hazard analysis. Combustion modes examined include pyrolysis/thermal decomposition, smoldering, and open flaming, and under ventilated flaming combustion.

The body of work indicates that victims exposed to products of combustion from flaming polyurethane will result in \%COHb's generally consistent with simple CO exposure, despite the clear toxicological role of HCN. The N-gas fractional effective dose methodology for asphyxiant gases is an appropriate methodology for prediction of incapacitation due to exposure to products of combustion from flaming polyurethane.

Conversely, there is significant scientific evidence that smoldering polyurethane foam produces as yet unidentified toxic species that results in deaths during the exposure and that the N-gas fractional effective dose methodology is not appropriate for smoldering combustion. Pyrolysis/thermal decomposition results in post-exposure deaths, consistent with irritant gases. The N-gas model is also not appropriate for pyrolysis/thermal decomposition.

There are significant limitations in the experimental methods available that have had a negative impact on the study of toxic hazards. Adsorption and transport of toxicants on smoke particles, loss of toxicants to walls, and more chemically complex toxicants tend to be little studied or considered. There is a need to encourage more sophisticated chemical and physical analysis of fire effluents for complex toxic organic species. It can be argued that there is still a place for animal models when analytical methods and our mechanistic understanding of toxicology of complex organic species are lacking.
\end{abstract}

KEYWORDS: toxic hazard, polyurethane, carbon monoxide, hydrogen cyanide, N-gas model

\section{INTRODUCTION}

Flexible polyurethane foam is widely used in upholstered furniture and in mattresses. The general view in the fire science literature is that toxic hazards from flexible polyurethane foam are primarily from carbon monoxide with some secondary contribution from hydrogen cyanide [1]. However, there have been recent observations by Blomquist et al. of isocyanates generated by fires involving nitrogen containing fuels [2,3]. Flaming combustion experiments in the cone calorimeter and burning of a couch in a ISO 9705 room indicate that isocyanates may contribute to the toxic hazard. In addition, there is evidence in earlier work that smoldering polyurethane foam produces important unidentified toxicants. This paper reexamines the body of literature to assess if the general view adequately represents the toxic hazards of flexible polyurethane foam. 
Carbon monoxide is widely recognized as the primary toxicant in fires (e.g., Gann et al. [4]). Fire deaths where the carboxyhemoglobin $(\mathrm{COHb})$ percent saturation is greater than $50 \%$ are generally attributed solely to CO. Deaths with \%COHb's in the range of 30-50\% are generally considered to be caused by $\mathrm{CO}$ in concert with other contributing factors. \%COHb's below $30 \%$ are generally considered to be too low for CO to be a contributing factor to fire deaths. \%COHb's of $30 \%$ are generally considered to be sufficient to cause incapacitation [5].

The role of carbon monoxide in fire and non-fire incidents was extensively studied and reviewed by Hirschler et al. [6]. Statistics of post mortem \%COHb's show clear differences between fire and non-fire victims in terms of \%COHb distributions. On the face of it, these differences are indicators of additional causal factors in fires. These differences were attributed to differences in the population characteristics between fire and non-fire victims by Debanne and Rowland in Chapter 8 of Hirschler et al. [6].

The role of hydrogen cyanide has been examined both in laboratory studies and forensically. Purser et al. [7] identified that at concentrations above $200 \mathrm{ppm}$, HCN causes hyperventilation and rapid incapacitation. In the range of 100-200 ppm, he found the effects to be both gradual and dose related. Pure gas studies with rats using CO and HCN by Levin et al. [8] showed that \%COHb's at death remained high, even when HCN was toxicologically significant. In tests where the percent contribution of HCN to deaths was set at $0,25,50$, and $75 \%$, the resulting \%COHb's were $83,73,69$, and $44 \%$, respectively. Of course with only $\mathrm{HCN}$, the \% $\mathrm{COHb}$ at death is zero. Esposito and Alarie [9] found similar results with mice in which $\mathrm{CO}$ and $\mathrm{HCN}$ were introduced together with each at $60 \%$ of the lethal concentration. The $\% \mathrm{COHb}$ was reduced from $65 \%$ for only CO exposure to $45 \%$ for the mixture. As such, though HCN is a contributing toxicant, HCN does not dramatically affect the \%COHb at death. The study by Yamamoto [10] showed little evidence of additive effects in terms of blood concentrations found. This is consistent with studies of fire deaths in actual fires. In these studies, there is no significant correlation of reduced \%COHb with measured blood cyanide concentrations [11-14]. In studies of individual events with large life loss Levin [15] found treating CO and HCN as additive useful in understanding the deaths that occurred while Birky et al. [16] found that significant HCN concentrations were only found in victims that had fatal levels of CO. The prevailing methodology in toxic hazard analysis is to consider CO and $\mathrm{HCN}$ as additive through the use of an N-gas fractional effective dose model [5]. While \%COHb's at death are not consistent with the N-gas model, the pure gas studies support the use of the $\mathrm{N}$-gas methodology with respect to the combined doses to reach incapacitation or death endpoints $[8,9,17]$.

Evaluation of toxic hazards are most often performed using the toxic gas model $[5,18]$. In this methodology, the generation rate of known toxic species are estimated based upon the burning rate of the item and the toxic species yields for the known toxic species. Toxic gas concentrations are predicted and the impact of the time dependent exposure to the various toxic gases is predicted. An alternate method less often used is the mass loss model $[5,18]$. In this method individual toxic gases are not identified. Rather, the material is burned or decomposed in a small scale test and the effect of the products on animals is assessed $[5,19]$. Predictions of toxic hazard are based upon the total fire effluent toxic potency as measured in the small scale test. The concentration of total fire effluents and the impact of the time dependent exposure to the total effluent are predicted.

Both methods are dependent upon the adequacy of the assessment of toxicity of the effluent. In the toxic gas method, all relevant toxic gases must be identified and included. 
In both methods, the combustion/decomposition of the material in the testing must represent the combustion/decomposition as it occurs in actual fire environments. Whether gas analysis or animal exposure is used, the testing must take account of the potential loss of toxic species in the sampling and presentation of the fire effluents.

\section{TOXIC HAZARD STUDIES OF FLEXIBLE PU FOAM}

Toxic hazard studies of flexible polyurethane foam include small scale testing and large scale testing. The combustion modes examined include thermal decomposition, smoldering, and open flaming, and under ventilated flaming combustion. Of the smallscale studies, only a few include smoldering foam. Several of the large-scale studies included smoldering foam. There is great confusion in the combustion toxicity literature concerning combustion modes. Many investigators considered there to be only two modes, flaming and non-flaming. They did not recognize that pyrolysis/thermal decomposition by an external heat source is vastly different than smoldering. While this distinction is well known in the fire dynamics community [20,21], this has not always been the case within the toxicity community. Smoldering involves a very specific combination of thermal decomposition to forma a char and subsequent char oxidation.

An instructive example can be drawn from the work of Anderson et al. [22]. They sought to initiate smoldering of flexible polyurethane foam by radiative heating. They found that smoldering could only be produced for incident heat fluxes in the range 6.1 to $6.8 \mathrm{~kW} / \mathrm{m}^{2}$. At higher heat fluxes the foam decomposes into a tar incapable of supporting smoldering, and at lower heat fluxes a brown char is formed but oxidation does not occur. With small heat sources, flexible polyurethane is decomposed to a tar in direct proximity of the heat source, exposing foam at a distance that can be charred and oxidized. In a crucible or other sample heating vessel used in small scale testing, the decomposition to a tar allows the remaining sample to contact the tar or the vessel so that the all important separation needed to cause smoldering is never possible. The sample decomposes to a tar entirely, and that tar further decomposes without char formation or oxidation. Smoldering and simple thermal decomposition are entirely different chemical and physical pathways.

\section{Small Scale Studies}

Most of the small scale testing work involves thermal decomposition and flaming combustion. In the thermal decomposition mode, the material is pyrolyzed by external heating. In the flaming mode, the material is heated externally sufficient to cause flaming. Much of this work was focused on the development of a small scale test method for screening materials with respect to toxicity. Additional work included the development of the N-gas model, in which major toxic gases are modeled such that contributions due to unknown toxicants can be identified.

In small scale testing using thermal decomposition of polyurethane foam, deaths tend to occur post-exposure and the rats are found to have serious lung damage, consistent with irritant effects [23-29]. The results are not consistent with the N-gas model. There has been extensive study of the thermal decomposition of polyurethanes. The early work in this area was carried out by Woolley [30] (and numerous F.R. Notes) at the UK Fire Research Station. He recognized that at low temperatures of $200-300^{\circ} \mathrm{C}$, thermal decomposition of flexible polyurethanes yields a yellow smoke that contains essentially all of the nitrogen originally in the foam. This smoke appeared to be stable up to temperatures of about $800^{\circ} \mathrm{C}$, when decomposition occurs to yield hydrogen cyanide and 
small molecule nitriles. In later work Woolley et al. [31] examined the fate of these small molecule nitrogen containing species in the flame zone. They found that these compounds were at least in part reacted to yield nitrogen oxides and molecular nitrogen. Metcalfe et al. [32-35] studied the pyrolysis of several nitriles and para-toluene isocyanate to establish mechanisms for the generation of hydrogen cyanide. Chambers and Reese [36-38] studied the thermal decomposition of polyurethanes. They found that the yellow smoke was a polyurea based upon TDI and that the polyurea decomposes above $600 \mathrm{C}$ to generate a wide range of nitriles and hydrogen cyanide. These studies give hints for processes during smoldering, but since these studies were conducted in a non-oxidative environment, smoldering necessarily involves additional oxidative chemistry not present in the pyrolysis/thermal decomposition.

In small scale testing using flaming combustion, animal deaths occur during the exposure with \%COHb consistent with $\mathrm{CO}$ poisoning [1]. In some small scale studies insufficient polyurethane foam could be tested in the apparatus to achieve lethal conditions. No deaths occurred at $70 \%$ of the fatal dose in the N-gas model [25-29].

In small scale testing using smoldering combustion, there is very limited data. Hilado et al. [39] performed limited testing in which reproducibility was poor and no attempt was made to vary the concentration of combustion products. The primary toxicant was clearly not CO, based both on the relatively low levels of CO generated and based upon the post-exposure nature of the deaths. Oxygen depletion and temperature were excluded as potential causes of death. No \% $\mathrm{COHb}$ data was reported and there were no tests at higher loadings to assess the nature and potential for deaths during exposure.

Condit et al. [40] investigated the incapacitation of rats due to exposure to the products of smoldering polyurethane. The \%COHb's found at incapacitation were $42-49 \%$, as compared to \%COHb's in range $50-55 \%$ for incapacitation due to $\mathrm{CO}$ alone in pure gases studies. As such, the effects of other unidentified toxicants were present but small. Thermal effects, oxygen depletion, and $\mathrm{CO}_{2}$ were excluded as playing a role. No post-exposure deaths were reported.

\section{Large Scale Studies}

The large scale toxicity testing used burn facilities of one to three interconnected enclosures. The animals were typically exposed in chambers to gases extracted from these spaces, rather than exposing the animals to the environment directly. This approach is intended to minimize the effects of thermal exposure that may affect interpretation of the toxicity data and the approach allows the exposures to be engineered to essentially constant concentrations.

Alarie et al. [41] conducted upholstered chair room scale tests. They used a cigarette ignition source with transition to flaming after about an hour. Mice were exposed to smoke extracted from the test room into an exposure chamber. Animal deaths occurred during the flaming period and were consistent with $\mathrm{CO}$ and $\mathrm{HCN}$ exposure.

Braun et al. [25] found that for flaming combustion of polyurethane foam, that CO and HCN could explain the mortality of rats in full scale tests. In smoldering tests, conditions required to cause deaths were not achieved, either within or after the exposure. It was, however, noted that similar loadings in small scale thermal decomposition tests did result in post-exposure deaths. This was identified as an area requiring additional study. Notably HCN was not generated during smoldering of the polyurethane foam. 
In a follow-up study Braun et al. [42] confirmed the prior findings that $\mathrm{CO}$ and $\mathrm{HCN}$ could explain flaming polyurethane combustion toxicity results for animals exposed in chambers using the N-gas modeling approach. They extended this result to conditions where the foam smoldered for 1.5-2 hours and was then forced to flame. All animal deaths occurred during the flaming stage and animals were exposed in separate exposure chambers. Subsequent single compartment smoldering work in this study used animals both within the same compartment as the smoldering polyurethane and in the usual exposure chambers. The deaths observed in the exposure chambers were consistent with the N-gas model. However, the results for the animals within the compartment were strongly inconsistent with the $\mathrm{N}$-gas model. In addition, deaths were found to occur primarily within the exposure. These results indicate that some additional toxic species were acting to cause the observed deaths during the exposure. Further, the fact that the small scale thermal decomposition testing yielded post-exposure deaths and actual in situ smoldering resulted primarily in deaths during the exposure indicates that the toxic species in thermal decomposition and smoldering are likely different. The fact that the doses of CO exposing the in situ rats was far below that required to explain their deaths indicates that this unidentified toxic species was potent.

It is well know that under ventilated compartment fire combustion leads to much increased yields of CO [43]. Similarly, external flaming at the compartment vent can substantially consume the CO produced in the room. The only study where animals were exposed to products of combustion of a ventilation limited fire including significant portion of flexible polyurethane was the work of Grand et al. [44]. Grand et al. used a fully furnished residential room and exposed the animals in a target room down a hallway from the fire compartment. They exposed one population of animals beginning at ignition of the fire. These animals were incapacitated just after flashover. Another population of animals was not exposed until just after the first population was incapacitated. Both populations died at the same time. The maximum conditions in the animal room were consistent with under ventilated burning with little external burning from the fire compartment. Carboxyhemoglobin concentrations at animal deaths ( 80\%) were consistent with the $\mathrm{CO}$ exposure. Carboxyhemoglobin concentrations at incapacitation ( 40\%) were generally consistent with $\mathrm{CO}$ and $\mathrm{HCN}$ exposure. Incapacitation via CO alone would have been at about $60 \% \mathrm{COHb}$.

Purser [27] reviewed under ventilated flexible polyurethane fire tests results of Kirk and Stark [45]. This study included only gas analysis of CO and HCN and no animal exposures. The use of a brominated phosphate fire retardant generally increased the ratio of HCN/CO. Their measurements also indicate that external burning consumed CO more than HCN.

Blomquist et al. [2,3] studied the production of isocyanates and amino compounds in flaming fires using the cone calorimeter and an ISO 9705 room test exclosure. They judged the relative toxic hazard contributions of $\mathrm{HCN}, \mathrm{CO}$, and isocyanates by expressing the average exhaust gas concentrations to "immediately dangerous to life or health" (IDLH) values reported by NIOSH, i.e., 50, 1200 and 3 ppm (value for methyl isocyanate was used to represent all isocyanates), respectively. For flexible polyurethane in the cone calorimeter, they found the isocyanates to be a greater hazard than $\mathrm{CO}$ and HCN. In a sofa test in the 9705 room test apparatus, they found isocyanates and CO contributions to be comparable (no HCN measurements were obtained). Isocyanates were measured using a midget inpinger flask and a glass fiber filter. This method is intended to collect both airborne and smoke particle borne isocyanates. 


\section{DISCUSSION}

\section{Discussion of the Limitations of the Available Methods and Results}

While the reviewed testing provides a basis for assessing the toxic hazards of flexible polyurethane foam, there are serious limitations and problems with the available toxic hazard test data.

The combustion modes used in the available testing include thermal decomposition, smoldering, open flaming, and under ventilated compartment burning. While a great deal of testing has been done using the thermal decomposition mode, this is the least important mode of generating toxic hazards, since this mode relies upon an external heat source to produce the toxic hazard. Smoldering hazards have largely been studied in nominally full scale compartments. While there is no standard test methodology for this combustion mode, the full scale combustion approach is reasonable, achievable, and appropriate. Open flaming hazards have been studied both in small scale and large scale, with general indications that the results are not seriously effected by scale. However, the work of Blomquist et al. [2,3] casts some doubt on the completeness of earlier work. Only a single investigation has explored toxic hazards in under ventilated compartment fires using animal exposures. That work is consistent with toxic hazards dominated by $\mathrm{CO}$ with contributions by HCN.

The review of the available testing points to several potential problems in the available test methods and results. The small-scale results for thermal decomposition are clearly not representative of the large-scale results with smoldering. The simple, though not always obvious, reason is that smoldering is not merely thermal decomposition. Smoldering is a solid phase combustion mechanism that includes low temperature thermal decomposition of the foam to form a char and subsequent combustion of the resulting char. The result is different, though not identified, products that are capable of causing death during the exposure as opposed to the irritant gases most often found to cause post-exposure deaths.

However, the available scientific work also points to an additional problem with existing methods of assessing toxic hazard. The large-scale work of Braun et al. [42] clearly indicates that toxic products are being lost when samples are drawn from the combustion compartment and pumped into an animal exposure chamber. Braun's work clearly identifies this as an issue in fire toxic hazard research. In the study of acid gases produced by thermal decomposition of gaseous fire suppression gases, it has long been know that in situ measurements are essential since sampling leads to line losses [46,47]. Even in situ measurements of acid gases after extinguishment show characteristic decay curves due to wall losses. This has also been observed in studies of $\mathrm{HCl}$ generated by thermal decomposition of PVC [48]. Concerns about this issue are clearly reflected in Kaplan, Grand, and Hartzell's review of principles and test methods in combustion toxicology, and proximity of the combustion source to the animal exposure chamber was clearly a design consideration in many of the small scale test methods [49]. Clearly, there is a tradeoff between the realism of the combustion in the small scale tests and the problems inherent in sampling in large scale tests. However, the both Braun et al. [42] and Grand et al. [44] seem to have at least found accommodations to resolve this issue. In Braun's smoldering experiments, the conditions of the smoldering compartment were such that animals could be directly exposed. In the fully developed fire scenario used by Grand et al., using a remote animal exposure room provided a realistic and operationally 
feasible method of exposing animals to environments that were not dominated by thermal effects and/or oxygen depletion. It is probably fair to say that if deposition of toxics in these test enclosures is significant, it is also reflective of realistic conditions as well.

Even when small chambers are attached directly to the combustion compartment, there are factors that lead to the loss of toxic species. The most obvious candidate for this phenomenon is loss of toxic species to the wall. Small-scale test chambers inherently have a larger surface area to volume ratio than large-scale room and the settling time for particles in the chamber is similarly reduced for small scale compartments. Another factor in small test method design is that flows are always inherently more laminar than are large-scale chambers. This leads to additional agglomeration of particles above the combustion source. These larger aerosols may exceed the respirable diameter of 10 microns so that the toxic species cannot reach the lungs. These effects are rarely mentioned and even less frequently investigated.

A significant observation was reported by Parent et al. [28] in a small-scale exposure of rats to the thermal decomposition products of polyurethane. Discussing the condition of the rats as they were removed from the chamber, Parent notes "they (the rats) were covered with yellowish-brown material, presumably smoke particles.” Prior work by Woolley [26] had found that this yellow smoke contained toluene diisocyanate (TDI), a highly toxic species. It is likely that Parent measured the toxic hazard of only a small fraction of the products of decomposition. Levin et al. [24] also alludes to the fact that $80 \%$ of the nitrogen is lost from the sample when heated to $370^{\circ} \mathrm{C}$, forming a residual char. The nitrogen lost was taken to have been contained in the yellow condensate visible on the walls of the exposure chamber. On a mass basis, the char has twice the nitrogen of the initial foam. This char was capable of generating HCN upon initiation of flaming later in the test. While Levin et al. [24] studied the char in detail, they did not characterize the yellow condensate on the walls. This condensate is likely related to the yellow smoke reported by Woolley [30]. However, since Woolley's method did not cause the formation of a char, it is unlikely that the yellow residue in Levin et al.'s work is simply TDI or a polyurea derived from TDI. Similarly, since Levin et al. did not actually smolder polyurethane, the yellow condensate is likely to be related to but different than the products of smoldering. No detailed characterization of the products of smoldering polyurethane foam is available in the scientific literature that can shed specific light on these issues.

Blomquist et al. [2,3] found the toxic hazard of isocyanates to be significant in both cone calorimeter and ISO 9705 testing. While these results are limited and lack animal exposures, they stand in stark contrast to the work of Braun et al. $[21,38]$ that found that animal deaths could be explained solely on the basis of CO and HCN. However, in the Braun et al. work [25,42] there was a small fraction of the deaths that occurred postexposure. This is not typical for toxic hazards dominated by CO and HCN. This trend was somewhat stronger for fire retarded foam. While the cause of death was not reported, the post-exposure death scenario is consistent with potential contributions of irritant gases. The effects of irritant gases may also have been minimized in these tests by the use of separate animal exposure chambers with smoke sampling lines connecting the compartment to the animal exposure chambers.

The observation of an unidentified toxicant in the smoldering tests by Braun et al. [42] are not unprecedented. The existence of an unidentified toxic species in fire environments was also discussed by Alarie, Memon, and Esposito [13] and by Anderson, Thompson, and Harland [11]. Both studies provide evidence that nitrogen-containing compounds are 
involved. Alarie et al. demonstrated that exposure to combustion products from nitrogencontaining fuels can lead to death with low \%COHb and low cyanide concentrations. Anderson et al. used detailed blood analysis of victims to demonstrate that organic nitriles are present in their blood that are not found in fresh blood or non-fire related postmortem blood.

Clearly, the limitations of the experimental methods available have had a negative impact on the study of toxic hazards. Adsorption and transport of toxicants on smoke particles, loss of toxicants to walls, and more chemically complex toxicants tend to be little studied. The shift away from animal testing in recent years has also seriously limited progress in toxic hazard assessment.

\section{Summary of the Current State of Knowledge}

The toxic hazard assessment methods in use today generally follow the $\mathrm{N}$-gas fractional effective dose methodology [5]. The review of toxicity testing literature indicates that this approach is satisfactory for flaming flexible polyurethane foam.

For pyrolysis/thermal decomposition of flexible polyurethane foam, the N-gas model does not predict the animal responses. Deaths occur post-exposure and appear to be the result of irritant gases derivative from TDI. Here the only available approach is using material based toxic potency wherein the total concentration of POC $\left(\mathrm{g} / \mathrm{m}^{3}\right)$ is used as a global measure of toxic hazard. Based upon the available data, the 30 minute exposure animal death endpoint is in the range of $23-40 \mathrm{~g} / \mathrm{m}^{3}$.

For smoldering of flexible polyurethane foam, the N-gas model does not predict the animal responses. Deaths occur primarily during the exposure and result from unidentified toxicant(s). HCN is not produced in measurable quantities in this combustion mode. Deaths occurred during testing over the period of 70-150 minutes with loadings in the range of $15-39 \mathrm{~g} / \mathrm{m}^{3}$, based on cumulative mass loss during smolder and the volume of the compartment.

For open flaming of flexible polyurethane foam, the N-gas model does predict the animal responses. Deaths occur during the exposure and result from combined exposure to CO and HCN. For under ventilated flaming combustion of flexible polyurethane foam, the Ngas model does predict the animal responses. Deaths occur during the exposure. Incapacitation appears to result from combined exposure to $\mathrm{CO}$ and HCN, while deaths are consistent with simple CO exposure.

While quantification of the irritancy of products of combustion of flexible polyurethane foam in a form suitable for toxic hazard assessment is not available, based upon the best evidence available, products of combustion for all combustion modes must be regarded as irritating based upon the production of isocyanates.

\section{CONCLUSIONS}

This body of work indicates that in victims exposure to products of combustion from flaming polyurethane will result in \%COHb's generally consistent with simple CO exposure, despite the clear toxicological role of HCN. The N-gas fractional effective dose methodology for asphyxiant gases is an appropriate methodology for prediction of incapacitation due to exposure to products of combustion from flaming polyurethane. 
Conversely, there is significant scientific evidence that smoldering polyurethane foam produces as yet unidentified toxic species that results in deaths during the exposure and that the N-gas fractional effective dose methodology is not appropriate for smoldering combustion. Pyrolysis/thermal decomposition results in post-exposure deaths, consistent with irritant gases. The N-gas model is also not appropriate for pyrolysis/thermal decomposition.

There are significant limitations in the experimental methods available that have had a negative impact on the study of toxic hazards. Adsorption and transport of toxicants on smoke particles, loss of toxicants to walls, and more chemically complex toxicants tend to be little studied or considered. There is a need to encourage more sophisticated chemical and physical analysis of fire effluents for complex toxic organic species. It can be argued that there is still a place for animal models when analytical methods and our mechanistic understanding of toxicology of complex organic species are lacking.

\section{REFERENCES}

[1] Hartzell, G., "The Combustion Toxicology of Polyurethane Foams," Journal of Cellular Plastics, 28, pp. 330-358, (1992).

[2] Blomqvist, P., Hertzberg, T., Dalene, M., and Sharping, G., "Isocyanates, aminoisocyanates, and amines from fires- a screening of common materials found in buildings," Fire and Materials, 27, pp. 275-294 (2003).

[3] Blomqvist, P., Hertzberg, T., Dalene, M., and Sharping, G., "Isocyanates in Fire Smoke,” Interflam 2004, Interscience Communications Ltd, London, (2004).

[4] Gann, R., Babrauskas, V., Peacock, R., and Hall, J., "Fire Conditions for Smoke Toxicity Measurement," Fire and Materials, 18 (3), pp. 193-199, (1994).

[5] Purser, D., "Toxicity Assessment of Combustion Products," The SFPE Handbook of Fire Protection Engineering, P.J. DiNenno, Editor-in-Chief, National Fire Protection Association, Quincy, MA, (2002).

[6] Hirschler, M., Debanne, S., Larsen, J., and Nelson, G., Carbon Monoxide and Human Lethality: Fire and Non-fire Studies, Elsevier Applied Science, London and New York, (1993).

[7] Purser, D., Grimshaw, P., and Berrill, K., Arch. Environ. HIth, 39 (6), pp. 394400, (1984).

[8] Levin, B., Paabo, M., Gurman, J., and Harris, S., "Effects of Exposure to Single or Multiple Combinations of the Predominant Toxic Gases and Low Oxygen Atmospheres Produced in Fires," Fund. And Applied Toxicology, 9, pp. 236-250, (1987).

[9] Esposito, F. and Alarie, Y., "Inhalation Toxicity of Carbon Monoxide and Hydrogen Cyanide Gases Released During the Thermal Decomposition of Polymers," Journal of Fire Sciences, 6, (3), pp. 195-242, (1988).

[10] Yamamoto, K., "Acute Combined Effects of HCN and CO with Special Reference to a Theoretical Consideration of Acute Combined Effects on the Basis of the Blood Cyanide and COHb Analyses,” Journal of Combustion Toxicology, 4, pp. 69-78, (1977).

[11] Anderson, R., Thompson, I., and Harland, W., "The Importance of Cyanide and Organic Nitriles in Fire Fatalities,” Fire and Materials, 3, (2), pp. 91-99, (1979). 
[12] Anderson, R., Watson, A. and Harland, W., "Fire Deaths in the Glasgow Area: II, The Role of Carbon Monoxide,” Med. Sci. Law, 21, (4), pp. 288-294, (1981).

[13] Alarie, Y., Memon, R., and Esposito, F., "Role of Hydrogen Cyanide in Human Deaths in Fire," Chapter 3, Fire and Polymers, G. Nelson, (ed.), ACS Symposium Series 425, American Chemical Society, (1990).

[14] Birky, M., Halpin, B., Caplan, Y., Fisher, R., McAllister, J., and Dixon, A., “Fire Fatality Study,” Fire and Materials, 3, (4), pp. 211-217, (1979).

[15] Levin, B., Recani, P., Landron F., Gurman, J., Clark, H., and Yoklavich, M., "Analysis of Carboxyhemoglobin and Cyanide in Blood from Victims of the DuPont Plaza Hotel Fire in Puerto Rico,” Journal of Forensic Sciences, 35, (1), pp. 151-168, (1990).

[16] Birky, M., Paabo, M., and Brown, J., "Correlation of Autopsy Data and Materials Involved in the Tennessee Jail Fire,” Fire Safety Journal, 2, pp. 17-22, (1979).

[17] Crane, C., Sanders, D., and Endecott, B., "Inhalation Toxicology: IX, Times to Incapacitation for Rats Exposed to Carbon Monoxide Alone, to Hydrogen Cyanide Alone, and to Mixtures of Carbon Monoxide and Hydrogen Cyanide," Civil Aeromedical Institute, FAA, Oklahoma City, Oklahoma, (1989).

[18] ISO, "Life Threat from Fires- Guidance on the Estimation of Time Available for Escape Using Fire Data,” ISO/DTS 13571, International Standards Organization, (2001).

[19] ISO, "Estimation of the Lethal Toxic Potency of Fire Effluents," ISO 13344, International Standards Organization, (2004).

[20] Drysdale, D.D., An Introduction to Fire Dynamics, Second Edition, John Wiley and Sons, New York, (1999).

[21] Ohlemiller, T., "Modeling of Smoldering Combustion Propagation," Progress in Energy and Combustion Science, 11, (4), pp 277-310, (1985).

[22] Anderson, M., Sleight, R., and Torero, J. "Downward Smolder of Polyurethane Foam: Ignition Signatures,” Fire Safety Journal, 35, (2), pp 131-147, (2000).

[23] Levin, B., Paabo, M., Fultz, M., Bailey, C., Yin, W., and Harris, S., “An Acute Inhalation Toxicological Evaluation of Combustion Products from Fire Retarded and Non-Fire Retarded Flexible Polyurethane Foam and Polyester,” NBSIR 83-2791, National Bureau of Standards, Washington, DC, (1983).

[24] Levin, B., Paabo, M., Fultz, M., and Bailey, C., "Generation of Hydrogen Cyanide from Flexible Polyurethane Foam Decomposed under Different Combustion Conditions," Fire and Materials, 9, (3), pp. 125-133, (1985).

[25] Braun, E., Levin, B., Paabo, M., Gurman, J., Holt, T., and Steel, S., "Fire Toxicity Scaling," NBSIR 87-3510, National Bureau of Standards, Gaithersburg, MD, (1987).

[26] Braun, E., Gann, R., Levin, B., and Paabo, M., "Combustion Product Toxic Potency Measurements: Comparison of a Small Scale Test and Real-World Fires," Journal of Fire Sciences, 8, pp. 63-78, (1990).

[27] Purser, D., "The Development of Toxic Hazard in Fires from Polyurethane Foams and the Effects of Fire Retardants," Flame Retardants '90, Elsevier Applied Science, pp. 206-221, (1990). 
[28] Parent, R., Dilley, J., Martin, S., and McKee, R., “Acute Toxicity in Fischer Rats of Smoke from Non-flaming Combustion of Tex Flexible Polyurethane Foams," J. Comb. Toxicology, 6, pp. 185-197, (1979).

[29] Levin, B., Paabo, M., Bailey, C., and Harris, S., "Toxicity of the Combustion Products from a Flexible Polyurethane Foam and a Polyester Fabric Evaluated Separately and Together by the NBS Toxicity Test Method," First International Symposium on Fire Safety Science, Grant and Pagni (eds.), Hemisphere Publishing Corp., Washington, DC, pp. 1111-1122, (1986).

[30] Woolley, D., "Nitrogen-containing Products from the Thermal Decomposition of Flexible Polyurethane Foams," Br. Polym. J., 4, pp. 27-43, (1972).

[31] Woolley, W., Fardell, P., Atkinson, A., and Verrall, A., "Conversion of Fuels Containing Nitrogen to Oxides of Nitrogen in Hydrogen and Methane Flames," Fire and Materials, 2, (3), pp. 122-131, (1978).

[32] Metcalfe, E., Booth, D., McAndrew, H., and Woolley, W., "The Pyrolysis of Organic Nitriles,” Fire and Materials, 7, (4), pp. 185-192, (1983).

[33] Metcalfe, E., Harman, A., and Fardell, P., "The Formation of Hydrogen Cyanide during Methacrylonitrile Pyrolysis," Fire and Materials, 11, pp. 45-47, (1987).

[34] Metcalfe, E., and Sonya-T-Eternmad-Rad, “The Pyrolysis of Benzonitrile,” Fire and Materials, 17, pp. 33-37, (1993).

[35] Metcalfe, E., and Marks, S., "The Pyrolysis of Para-Toluene Isocyanate," Combustion and Flame, 107, pp. 260-270, (1996).

[36] Chambers, J., and Reese, C., "The Thermal Decomposition of some Polyurethane Foams,” The British Polymer Journal, pp. 48-53, (1976).

[37] Chambers, J., and Reese, C., "The Thermal Decomposition of some Tolylene Bis-Carbamates,” The British Polymer Journal, pp. 41-46, (1977).

[38] Chambers, J., Jirieny, J., and Reese, C., "The Thermal Decomposition of Polyurethanes and Polyisocyanurates," Fire and Materials, 5, (4), pp. 133-141, (1981).

[39] Hilado, C., Brandt, D., and Brauer, D., "An Apparatus and Procedure for Evaluating the Toxic Hazard of Smoldering Seating and Bedding Materials," $J$. of Combustion Toxicology, 5, pp. 400-407, (1978).

[40] Condit, D., Malek, D., Canciolo, A., and Hofrichter, C., "Life Hazard Evaluation of Flexible Polyurethane Foam/Fabric Composites Typical of Cushioned Upholstered Furniture,” J. of Combustion Toxicology, 5, pp. 370390, (1978).

[41] Alarie, Y., Stock, M., Matijak-Schaper, M., and Birky, M., “Toxicity of Smoke during Chair Smoldering Tests and Small Scale Tests Using the Same Materials," Fundamental and Applied Toxicology, 3, pp. 619-626, (1983).

[42] Braun, E., Levin, B., Paabo, M., Gurman, Clark, H., and Yoklavich, M., "Large-scale Compartment Fire Toxicity Study: Comparison with Small-scale Results,” NBSIR 88-3764, National Bureau of Standards, Gaithersburg, MD, (1988).

[43] Gottuk, D., and Lattimer, B., "Effect of Combustion Conditions on Species Production," The SFPE Handbook of Fire Protection Engineering, P.J. DiNenno, Editor-in-Chief, National Fire Protection Association, Quincy, MA, (2002). 
[44] Grand, A., Kaplan, H., Beitel, J., Switzer, W., and Hartzell, G., "An Evaluation of Toxic Hazards from Full-scale Furnished Room Fire Studies," Fire Safety: Science and Engineering, ASTM STP 882, T.Z. Harmathy (ed.), American Society for Testing and Materials, pp. 330-353, (1985).

[45] Kirk, P., and Stark, G., "Flexible Polyurethane Foam - Large Scale Fires of Industrial Loads of Seating Cushions,” Her Majesty's Stationary Office, London, pp. 1-18, (1975).

[46] DiNenno, P., "Halon Replacement Clean Agent Total Flooding Systems," The SFPE Handbook of Fire Protection Engineering, P.J. DiNenno, Editor-in-Chief, National Fire Protection Association, Quincy, MA, (2002).

[47] Forssell, E.W., Back, G.G., Beyler, C.L., DiNenno, P.J., Hansen, R., and Beene, D., “An Evaluation of the International Maritime Organization's Gaseous Agents Test Protocol,” Fire Technology, 37, (1), pp. 37-67, (2001).

[48] Bertelo, C., Carrol, W., Hirschler, M., and Smith, G., "Thermal Decomposition of PVC: Kinetics of Generation and Decay of $\mathrm{HCl}$ in Large and Small Systems and the Effect of Humidity," Fire Safety Science, Proceeding of the First International Symposium, Grant and Pagni (eds.), Hemisphere Pub. Co. Washington, DC, pp. 1079-1088, (1986).

[49] Kaplan, H., Grand, A., and Hartzell, G., Combustion Toxicology, Principles and Test Methods, Technomics Publishing Co., Lancaster, PA, (1983). 